\title{
Expert's comment concerning Grand Rounds case entitled "Diagnosis and treatment of a rectal-cutaneous fistula: a rare complication of coccygectomy" by Eyal Behrbalk, Ofir Uri, Charles Maxwell-Armstrong and Nasir A. Quraishi (Eur Spine J; DOI 10.1007/s00586-014-3579-1)
}

\author{
John Abercrombie ${ }^{1}$
}

Received: 4 February 2016/Revised: 4 February 2016/Accepted: 4 February 2016/Published online: 18 April 2016

(C) Springer-Verlag Berlin Heidelberg 2016

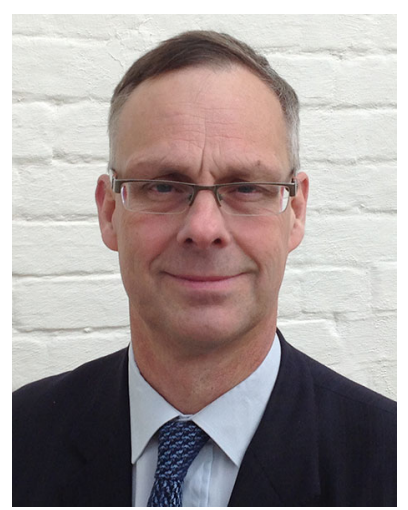

The authors present an unusual case of a recto-cutaneous fistula through a coccygectomy wound. MRI is generally considered to be the most useful diagnostic test but, interestingly, it failed to make the diagnosis in this instance. Sinography, the injection of contrast into a sinus tract, would have been a valid alternative imaging modality in this case.

Passage of a probe through a fistula tract is a standard technique in cryptoglandular anal fistula surgery. However, this is not always easy and can result in the creation of false tracts. It is not a technique that should be employed by a surgeon who is unfamiliar with it. The use of dye to confirm an enterocutaneous fistula is a recognised but seldom employed method. It is often rather messy and can lead to widespread staining of the tissues. The method was very helpful in this case.

The use of a defunctioning colostomy in this case was a sensible precaution to allow the rectal repair, fashioned in an infected field, to heal.

John Abercrombie

john.abercrombie@nuh.nhs.uk

1 Department of Surgery, Queen's Medical Center,

Nottingham NG7 2UH, UK 